\title{
282 years of orthodontic history
}

\author{
Julien PHILIPPE
}

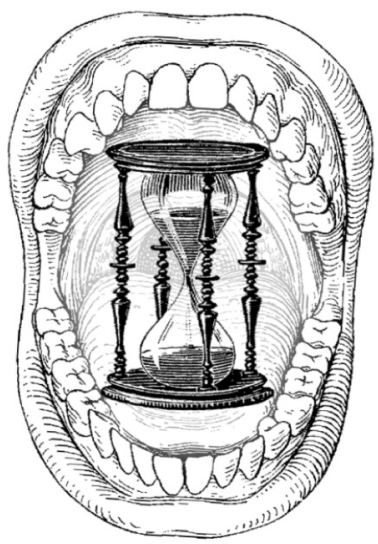

\section{ABSTRACT}

Orthodontics has been developing for 282 years. We can distinguish an initial period when practitioners limited themselves to "straightening" teeth that were out of position. Then, under the influence of Edward Hartley Angle, they devoted their efforts to correcting "malocclusions." Now, during its third period, orthodontics has divided itself into two branches. The American school believes the shape and size of basal bone is genetically determined and that treatment should be limited to the dentition, which must be positioned in conformity to precisely defined standards. But the European school is persuaded that basal bone can be modeled by the play of functional forces, which treatment can change and thereby adjust growth and development. What will be the guiding principle of the orthodontics of tomorrow?

\section{KEYWORDS}

Development of orthodontics

History

Orthodontic doctrines. 
The historian of orthodontics is extremely fortunate. He knows exactly when its history began: it was in 1728 with the publication of Pierre Fauchard's book ${ }^{1}$. So it has been a 282 year long story that unfolds before his eyes, whose development he can study in detail.

\section{THE “STRAIGNTENING” ERA}

The first period was the epoch devoted to the "straightening" of one or more anterior teeth that were out of place. At best, orthodontists learned from LeFoulon, 1841, how to enlarge a deformed arch, such as one that is " $V$ " shaped. In making these adjustments practitioners did not attempt to improve a poor relationship between the upper and lower arches no matter how removed from normal it might be, because, even if they wanted to, they had no available means to do anything about it. This conception of the nature of orthodontics that saw the light of day with Pierre Fauchard reached its culminating point a century and a half later when John Nutting Farrar published a three volume tome, from 1888 to 1897, whose 1571 pages described countless procedures for moving teeth and correcting "irregularities" (a term that had a prominent place in the book's title, A Treatise on the Irregularities of the Teeth and their Correction) without once mentioning occlusion.

Most of the practitioners of this first era of orthodontics thought that these "irregularities" were caused by overretention of deciduous teeth, heredity, or by "degeneracy."
It seems that this orthodontic stream flows through three quite distinct stages that sometimes give the observer the impression that he is inspecting three different species of orthodontics.

This era came to an end during the final years of the $19^{\text {th }}$ century thanks to the intelligence of three men:

- Norman W. Kingsley, who, in 1892, proposed a technique for "jumping the bite" that was the first method ever suggested for correcting a retruded mandible. Kingsley thought that when the arches were placed and held in good relationships the condyles would grow accustomed to their new positions. This same Kingsley invented the extra-oral force system designed to retract a protruded maxillary arch.

- Calvin Case, who in 1896 invented inter-maxillary elastic traction, another method for correcting inter-arch discrepancy.

- Edward Hartley Angle who in 1899 proclaimed the end of the orthodontic era based on treatment of irregularities of teeth and announced, "We define orthodontics as the science whose objective is correcting malocclusions of the teeth."

While French and English pioneers had inspired the first era of orthodontics, it was the doctrines of these three Americans that would dominate the progression of the specialty's second stage. 


\section{THE ERA OF CORRECTING MALOCCLUSIONS}

The second era of orthodontics, which occupied the period between 1899 and 1940, was characterized by the quest for a perfect occlusion that Davenport described precisely and was the epitome of Angle's method. Curiously, this perfection is not sought after to ensure the health of the Tempero-Mandibular-Joint but rather to preserve the integrity of the dentition. Without a perfect, that is to say an undamaged and undiminished, occlusion, the dentition would fall out of equilibrium and eventually be destroyed. Angle added another reason for this search for the ideal: a wellrestored occlusion would stimulate renewed bone growth that would restore the balanced appearance to the face that it would have had if the perturbation of the malocclusion had not developed. Without saying it in so many words, Angle was, in fact, an orthopedist in the sense that we now use the word.

\section{THE BIFURCATION}

During the third stage two different conceptions of orthodontics would develop side by side.

The American school, led by Alan Brodie and Charles Tweed, believed that growth is genetically determined. Accordingly, orthodontic forces can have no effect on basal bone but can only, in Strang's words, "camouflage" their defects by moving teeth to their correct positions on dental arches whose size cannot be modified. To obtain this objective orthodontists often had to "sacrifice" four and,
The etiology of malformations is dominated by functional factors that otolaryngologists can sometimes treat. But such treatment is not followed up by re-education techniques that have only recently come into the picture.

This second orthodontic epoch concluded in 1940 in a veritable scientific revolution. In the United States orthodontists stopped believing that function had a role to play in growth. Everything, they decided, depended on the genetic data bank or, in other terms, they concluded that Darwin had triumphed over Lamarck. But Europe, isolated from the United States for almost a decade during World War II was not affected by this revolution for many years. Instead on its side of the Atlantic it developed therapies based on the interplay of functional forces.

sometimes, even eight teeth and treat patients with sophisticated fixed appliances that were able to deliver precisely determined forces to the teeth and their roots.

Orthodontist began to take more and more measurements of the form and position of skeletal structures and the goal of therapy became an attempt to adjust the measurements of each patient to fit, as closely as possible, a pre-determined average, the biometric norm, considered to be an ideal, falsely, in our opinion ${ }^{2}$. One 
of the benefits of this conception became the extension of the delivery of orthodontic care to adults, thanks, in part, to orthognathic surgery, the collaboration of periodontists, and the use of appliances that were not readily visible.

But European orthodontists took another path, becoming convinced that the play of functional forces models the face and that by modifying this interaction with appliances that were passive, the unique feature of the method, they would be able to change the orientation of growth and thereby correct malformations. By reestablishing nasal ventilation and correcting oral malfunctions they believe they can exert a beneficial effect on the shape of the face and even on the general health of the patient.

By focusing on etiology, they have been able to develop new procedures for intercepting and preventing anomalies.

For many years there has been a deep chasm separating the supporters of each theory and the arguments between the partisans of the two groups were often acrimonious but eventually the tone of the debate began to soften. One could find, first in Europe, and then in the United States, practitioners who employed both approaches, functional for young children and a detailed mechano-therapy for adolescents. But critics, some from the "evidence-based" school of thought, are now attacking two-stage treatment as a therapy that is more costly and more time-consuming but without any quantifiable benefit.

After having first awarded a lead position to "correcting irregularities of the dentition," and then to treatment of malocclusion, and, most recently, to conforming to a biometrical norm, where will the orthodontics of the future focus its attention? Intoxicated nowadays by the ease with which it has conquered the demands and pitfalls of appliance manipulation will orthodontics turn its attention in the future to therapies that are merely cosmetic or will it soar to new biological heights by constructing a dento-gnatho-facial architecture and a life-long commitment to healthy functional behavior for all patients that will bestow upon them the best chances for oral health and facial harmony, thus increasing their happiness and their longevity.

\section{REFERENCES}

1. Philippe J. Histoire de I'orthodontie. Paris : S.I.D., 2003.

2. Philippe J. Convictions orthodontiques. Paris : S.I.D., 2006. 